\title{
Evolution of Primate Cognition
}

\author{
RICHARD W. BYRNE \\ University of St. Andrews
}

\begin{abstract}
Comparative analysis of the behavior of modern primates, in conjunction with an accurate phylogenetic tree of relatedness, has the power to chart the early history of human cognitive evolution. Adaptive cognitive changes along this path occurred, it is believed, in response to various forms of complexity; to some extent, theories that relate particular challenges to cognitive adaptations can also be tested against comparative data on primate ecology and behavior. This paper explains the procedures by which data are employed, and uses the best currently available evidence to derive a proposal for some of the stages through which human cognition evolved, before the last common ancestor with a nonhuman, and the reasons that cognitive adaptations were favored in primate evolution.
\end{abstract}

\section{INTRODUCTION}

The excitement for psychologists of investigating the cognition of primates derives from what it may reveal about the evolution of cognition in one specific primate, Homo sapiens. Primate data gives us direct insight into the evolution of cognitive capacities that arose before the last common ancestor we share with our closest relatives, the two species of chimpanzee; for more recent evolution, archaeology and paleontology take over, but interpretation of their data can also be informed by primate comparisons.

Humans are highly specialized for intelligence, to judge by the morphological correlate of cognitive function, the brain. The human brain is about six times as large as that of a typical mammal of human body size (Jerison, 1973). Adult brain size is a consequence of both brain size at birth and postnatal brain growth. Some primates specialize in one or other of these methods, and in general there is a trade-off between them, with the extent of postnatal brain growth inversely related to relative neonatal brain size (Harvey \& Clutton-Brock, 1985). Humans lie off this regression, both methods contributing to the development of a brain uniquely large for a primate, with disproportionate enlargement of association areas (Deacon, 1990). Humans suffer from this in two ways. Large brain size at birth, in conjunction with a narrowed pelvis associated with efficient modern bipedal-

Direct all correspondence to: R. W. Byrne, University of St Andrews, School of Psychology, St Andrews, Fife KY16 9JU, Scotland. E-mail: rwb@st-and.ac.uk. 
ism, has the consequence of difficulties and danger to mother and child during birth. Yet, much postnatal brain growth is still necessary to reach the adult size, so that the human infant is unusually helpless at birth and dependent for several years on time-consuming parental care. In particular, the costs of lactation to a human mother are substantially a result of brain size, since brain tissue is metabolically expensive, and for a time in early childhood the brain makes up 50\% of basal metabolic rate (BMR; Armstrong, 1983; Milton, 1988). Even as an adult, the brain's contribution to BMR falls only to 20\%, the highest fraction in proportion to its size of any organ (Aiello \& Dunbar, 1993). Because neural tissue is unstable, this energy supply has to be kept up remorselessly: even anoxia for a few minutes risks permanent brain damage. Evolution cannot result in net disadvantage for a species: in all cases, when "disadvantages" arise in evolution, they do so as a side effect of changes having overwhelming benefits overall. The numerous costs attendant on human cognitive specialization imply that intelligence has had major evolutionary advantages during the evolution of the species.

There are several possible approaches to discovering when and how these evolutionary advantages had their effect. Archaeological and paleontological examination of the traces left by human and nonhuman primate ancestors reveals signs of behavior (Mithen, 1996). Direct fossil evidence of behavior is rare except in recent human ancestry, and even categorization of skeletal material into "species" is not straightforward (Tattersall, 1995), since interbreeding is a matter of behavioral choice, not body shape. Even for the most recent extinct hominids, the Neanderthals, estimates of the relationship to modern humans have varied frequently in recent years (Stringer \& Gamble, 1993). ${ }^{1}$ Further back in time, with fossils of early hominids and apes, the problems only become more severe. While it is tempting to treat a fossil species as ancestral to whatever extant species it most resembles, the fact is that the fossil may have had no descendants, and its existence may only document one of the many lineages ending in extinction.

At the opposite extreme, the "design" of any organism can give clues as to how and why it evolved (Dawkins, 1986). With this logic, the organization of the modern mind can be "reverse engineered" to deduce past evolutionary processes (Barkow, Cosmides \& Tooby, 1992). Of course, the environment of most modern humans is so recent, in evolutionary terms, as to have had little impact by genetical selection; we are, in a sense, adapted to a vanished world. In taking the argument-from-design approach, human characteristics are assumed to be adapted to living as hunter/gatherers in the Pleistocene (Tooby \& Cosmides, 1992), a period that lasted for millions of years. Unfortunately, knowledge of the Pleistocene period of human ancestry is itself imperfect (Foley, 1996). Worse, several of the extinct hominids whose stone tools define the period are now considered not to be closely related to modern humans (Mellars \& Stringer, 1989). Knowledge of the Pleistocene is least sketchy in Europe, the Near East and Asia, where numerous bones, tools and living floors of Homo erectus, H. heidelbergensis, and $H$. neanderthalensis allow some fairly clear pictures of their lives to be built up, including tantalizing signs of big-game hunting with spears at 400 thousand years ago, and at more recent dates, burial and use of fire. However, the evidence from molecular systematics points to a relatively recent, African origin for all modern human populations (Mountain, 
1998); H. erectus, H. heidelbergensis, and H. neanderthalensis would then be seen as derived from a much earlier "Out of Africa" spread, only side-branches of a "bushy" tree of hominid evolution. In this case, their cultural and cognitive achievements parallel but may not have affected those of Homo sapiens. Only from the last 40 thousand years is there any evidence that direct human ancestors pursued a lifestyle close to that of modern hunter/gatherers, based on co-operative hunting of big-game, use of fire, home-bases and living-shelters. This period is not orders of magnitude greater than, say, the 8 thousand years of Neolithic agriculture, so the logic of "adaptation to the Pleistocene" is compromised. In reality, some of the most convincing accounts given of the likely evolutionary origins of modern human traits-patterns of infanticide and homicide (Daly \& Wilson, 1990, 1996), partner choice and matrimonial systems (Buss, 1989; Wilson \& Daly, 1992) - are based on design principles that apply to apes, monkeys, and even nonprimates, not specifically to Pleistocene hunter/gatherers. Clearly, important human traits have a much greater antiquity than the Pleistocene.

Fortunately, for any characteristic except those that evolved solely in the last few million years of human ancestry, there is an additional source of evidence available: the nonhuman primates, and (for more ancient characteristics) other species of animal. This comparative evidence is particularly valuable for understanding the evolution of cognition (Byrne, 1995b), because behavior as well as form can be studied. Animal behavior is available to be observed systematically, in most cases within essentially the environment in which it evolved, and manipulated in experiments in the wild and in captivity. Already, comparative primate analyses inform the data of archaeology and palaeontology (Mithen, 1996). Because there is no doubt that each living species shares a common ancestor with humans at some point in the past, the species distribution of a characteristic contains evidence about its origins in the human lineage. This paper will attempt to explain how these data can be read, and outline the current range of theories that they support.

\section{APPROACH}

To describe "the evolution" of any characteristic, morphological or behavioral, requires at least two contributions. Each contribution may be understood as an answer to the same question, "How did the characteristic evolve?," but neither provides a complete answer on its own. In the first place, we may inquire about the historical aspects: at what approximate date did the characteristic first evolve in the lineage under consideration, in what ancestral species, and before or after which other characteristics. All of these questions may be addressed without touching on the second contribution, the causative aspects: what environmental features so significantly favored the new characteristic that natural selection perpetuated it in subsequent generations, ${ }^{2}$ and out of what original set of genetically encoded characters was it selected.

Although in reality the causative and historical aspects are intimately and logically related, the evidence for each is of a different kind, so it is convenient to discuss the two separately. What both share is that the evidence we have available is necessarily of an indirect nature; the process of evolution is not subject to direct experimental testing. (This 
applies to all evolutionary claims, not merely to those about cognition. However, the difficulties are exacerbated by the fact that cognitive mechanisms themselves are knowable only indirectly, from the organization of observed behavior.) For these reasons, in this paper I will endeavor to make explicit the processes by which evidence has been used to deduce the evolutionary stages in primate cognition and their causes. The evidence itself is certainly imperfect, and refinements in data collection may result in changes to conclusions; but the important point is that the process of relating evidence to theory will remain the same.

\section{THE EVOLUTIONARY HISTORY OF PRIMATE COGNITION}

\section{Methodology for Inferring History}

Establishing a reliable pattern of descent. Reconstructing evolutionary history from the evidence of extant species depends on a reliable evolutionary phylogeny (Ridley, 1986). In such a taxonomy, species are grouped together in a way that reflects the relative recency of their divergence in the branching process of evolution. This is best derived by cladistic analysis (Hennig, 1966), in which species are put together into valid phylogenetic groupings, called clades, on the basis of possession of shared, derived characteristicsthat is, by genetically coded traits that arose in the common ancestor of the clade. The diagram produced by recursively grouping clades together is called a cladogram. (Note that, since "higher" groupings in the cladogram are based on fewer shared, derived features, there is inherently less certainty about the larger phylogenetic groupings: the precise delineation of the grouping "animals" is harder to establish than that of the grouping "Old World monkeys.") It is crucial for this grouping process to distinguish derived from primitive characteristics, retentions from earlier species. The grouping of "nonhuman great apes," formerly called Pongids, is not a valid phylogenetic grouping, because the shared characters that distinguish its members from humans (small brain, hairiness, etc.) are all primitive characters; thus there was no common ancestor of nonhuman great apes that was not also a human ancestor. (The proper clade here includes humans as well as nonhuman great apes.) Primitive characters are usually identified by comparison with an out-group, some definitely less closely related species; in this example, monkeys form an appropriate out-group, and indeed monkeys are smallerbrained and hairier than humans.

Convergent evolution, in which species share characters by independent evolution in separate lineages (such as the large bodies of both elephant and hippopotamus, unrelated species formerly grouped together as Pachyderms), has long been known to form a potential pitfall in this process. The traditional remedy has been to rely on complex and inherently unlikely structures, like the vertebral column, rather than simple adaptations with obvious utility, like wings. However, the discovery that portions of the immensely complex biological molecules are relatively inert structures not much subject to active selection has made classification by molecular similarity attractive to taxonomists (see Ridley, 1993); this is particularly the case with DNA, in which large sections of the 


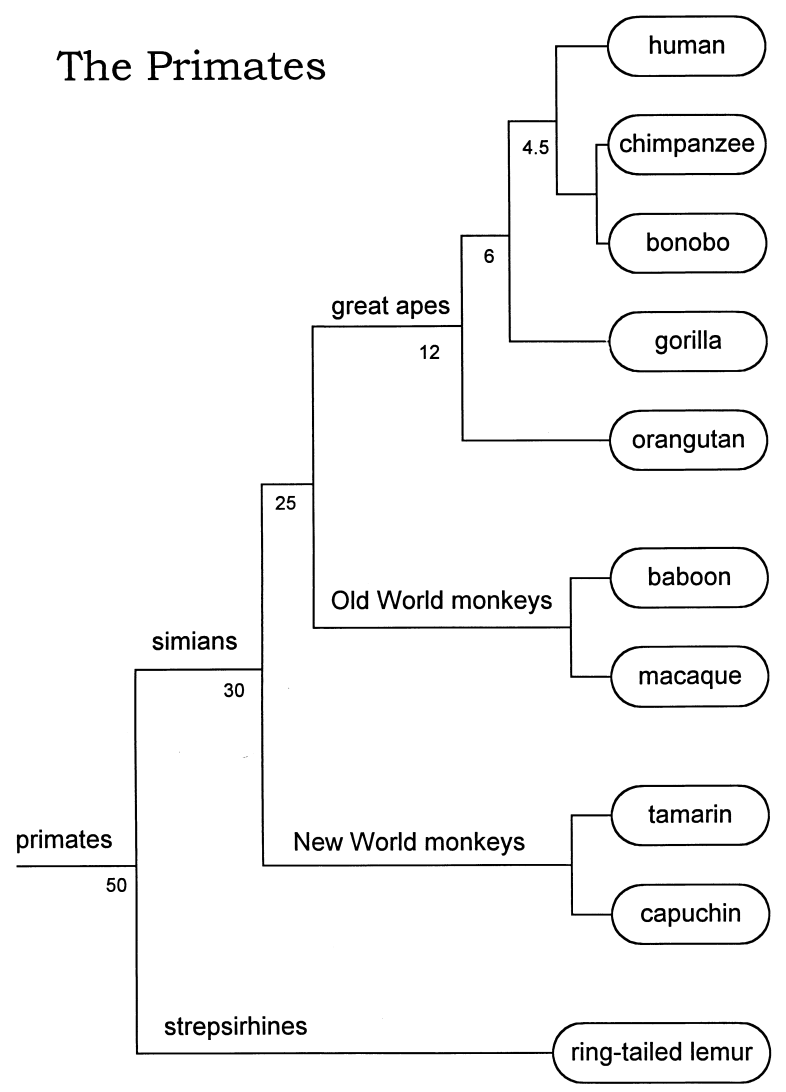

Figure 1. Primate phylogeny. Only those genera mentioned in the text as contributing evidence of cognition are included, and the main higher level groupings about which reliable deductions can be made are labeled. The numbers at some branch points are the approximate estimated dates of divergence, in millions of years, based on the calibration of setting orangutan/human to $12 \mathrm{Ma}$, which can be justified by the existence of Dryopithecine ape fossils at that date that show some derived characters of the orangutan. More often, a date of $16 \mathrm{Ma}$ is used for this, but this seems overly conservative since no possible orangutan ancestors are known that early (M. Köhler, pers. comm.).

molecule have no phenotypic expression at all, and DNA sequencing is now the preferred technique.

Cladistic analysis using DNA sequence data has amply confirmed the dramatic result of earlier, simpler methods of molecular classification: humans are far closer related to some nonhuman primates than was formerly thought (Jones, Martin \& Pilbeam, 1992). Instead of occupying an entirely separate clade to the apes, humans now appear deeply embedded within the African great ape clade (Figure 1). From the point of view of a chimpanzee or a bonobo, humans are a much closer relative than the Asian orangutan. The exact resolution of the relationships among the African apes has been controversial, but most modern evidence strongly supports the chimpanzee-human clade (Goodman et al., 1994; Kim \& Takenaka, 1996): chimpanzees are more closely related to humans than they 
are even to gorillas. Translating these relationships into estimates of likely dates for the divergence times is more problematic. The concept of a "molecular clock" depends on assuming that mutation rates have not changed significantly in recent geological time, and that most mutations are neutral, not an adaptive product of natural selection. Both these assumptions are likely to be realistic (and unexpressed portions of DNA may be chosen to ensure an absence of active selection), but calibration of the clock also depends on an accurate date for at least one ancestor species (i.e., for a branch point in the cladogram). For reasons already mentioned, identifying a fossil species as ancestral to a living one is hard, and finding the precise ancestor that corresponds to an identifiable branching point on a cladogram is harder still. Nevertheless, recent attempts to do so have agreed with the earliest molecular taxonomy, in estimating a likely date of only 4-6 million years ago for the last common ancestor we share with the two species of chimpanzee (Sarich \& Wilson, 1967; Waddell \& Penny, 1996). Furthermore, an early hominid from 4.4 million years ago has recently been found that possessed shared, derived characters of chimpanzees and humans, but lacked specific characters of the gorilla (White, Suwa \& Asfaw, 1994), suggesting that the real divergence time was nearer 4 than 6 million years ago. This relatively small span of human evolution, since divergence from the lines leading to other primates, encourages the possibility that significant aspects of human cognition evolved before the split, and can thus be studied by comparative analysis.

Inferring characteristics of extinct ancestors. Once a reliable phylogeny has been established, the process of using it to infer evolutionary history is a rather different one, which might be called evolutionary reconstruction (Byrne, 1995b). Each branch point in the cladogram identifies an extinct species that lived at and perhaps before the date given by a calibrated molecular clock. Each inferred species is definitely ancestral to all the living species in the clade that defines it, whether or not any fossil is ever found that might match it. To work out what such a species was like, we again examine the morphological and behavioral characteristics of its descendants. However, in this case all characteristics are relevant, not just the shared, derived ones. Characters found in all or most of the living descendants can be safely assumed to be derived from the extinct, deduced ancestor. (To suggest that evolution repeatedly converged on the same character, independently in many lines of descent, would be highly unparsimonious.) However, the robustness of this method in the face of species variation depends on the number of living species that can be examined, and in clades defined by only a few species uncertainty is introduced if there is any variation in characteristics. There are between two and three hundred species of primates, but most are monkeys and relatively few great apes survive, so that it is least straightforward to establish that part of the history of primate cognition of greatest interest for psychology.

Evolutionary reconstruction should be sharply distinguished from the use of living species as "models" of past phases in the evolution of other species, in particular of humans. The idea in that enterprise is that, while evidently each living species has evolved for just as long as any other since their lines of descent originally diverged, it is possible that all significant evolutionary changes might have been on one line rather than the other. 
In this case, one species would be in effect a "living fossil" of the other. Stasis of this kind is rare, however, and most likely when the environment is unusually constant, such as in the deep ocean. Modern Nautilus, the coelacanth Latimeria, and some bottom-living sharks are good examples of living fossils of very ancient forms. In contrast, it is inherently less likely that any primate species should have remained essentially unchanged for millions of years, and wildly improbable that a whole series of species should have done. Perhaps a living fossil of some early stage in primate and human evolution may exist - the tarsier is one candidate- but only evolutionary reconstruction of the ancestor concerned will allow us to identify any living fossil as such. Unfortunately, when the series "prosimian" (usually ring-tailed lemur), "monkey" (usually a macaque), "ape" (usually the chimpanzee) and human is used to illuminate evolution, this is more likely to be based on a misunderstanding of evolution as progressive, a discredited approach still retailed sadly often in the media, plus the ready availability of those three species in the laboratory.

The evolutionary path of cognition. Thanks to the revolution in taxonomic techniques, it is now clear which ancestral species can in principle be reconstructed. Those of greatest interest for cognition are species on the human lineage, including the ancestors of all primates, of all simians (the shared ancestor of tarsiers and simians will be difficult to reconstruct, with only one unusual genus, Tarsier, on one of the two branches), of Old World monkeys and apes, of all apes, of all great apes, of African great apes, and of specifically the chimpanzees and human.

At present there is adequate evidence to make generalizations only about the cognition of three of these species: the primate ancestor, the simian ancestor, and the great ape ancestor (see Figure 2). On current evidence, the earliest primates were not cognitively distinguished from most other mammals. Then, some time before $30 \mathrm{Ma}$ (millions of years ago), one branch of their descendants became specialized for more rapid learning, an adaptation that required substantially larger brain size in relation to body size. This ancestral population gave rise to all modern simians, the monkeys and apes, including humans. Subsequently, one branch of the simian lineage, ancestral specifically to modern great apes and ourselves, developed the ability to understand the causal connections between objects, actions and events, the mental states of other individuals, and the hierarchical organization of behavior. This adaptation was established before $12 \mathrm{Ma}$, but it is not clear whether it depended on an increase in absolute brain size, or a purely cognitive reorganization not much related to brain size. Because linguistic communication requires participants to model the mental states of interlocutors, understanding mental states was a crucial precursor to the development of language at some point in the hominid branch of the ape lineage. It is likely, since possession of language greatly increases the efficiency and sophistication of mental representation, that the representational ability of the great ape ancestors was nowhere near as elaborate as our own.

Even to make these pronouncements about the historical development of cognition in three of the populations ancestral to modern humans, is to rely on data that are not universally accepted-for instance, which primate is capable of which particular feat. 


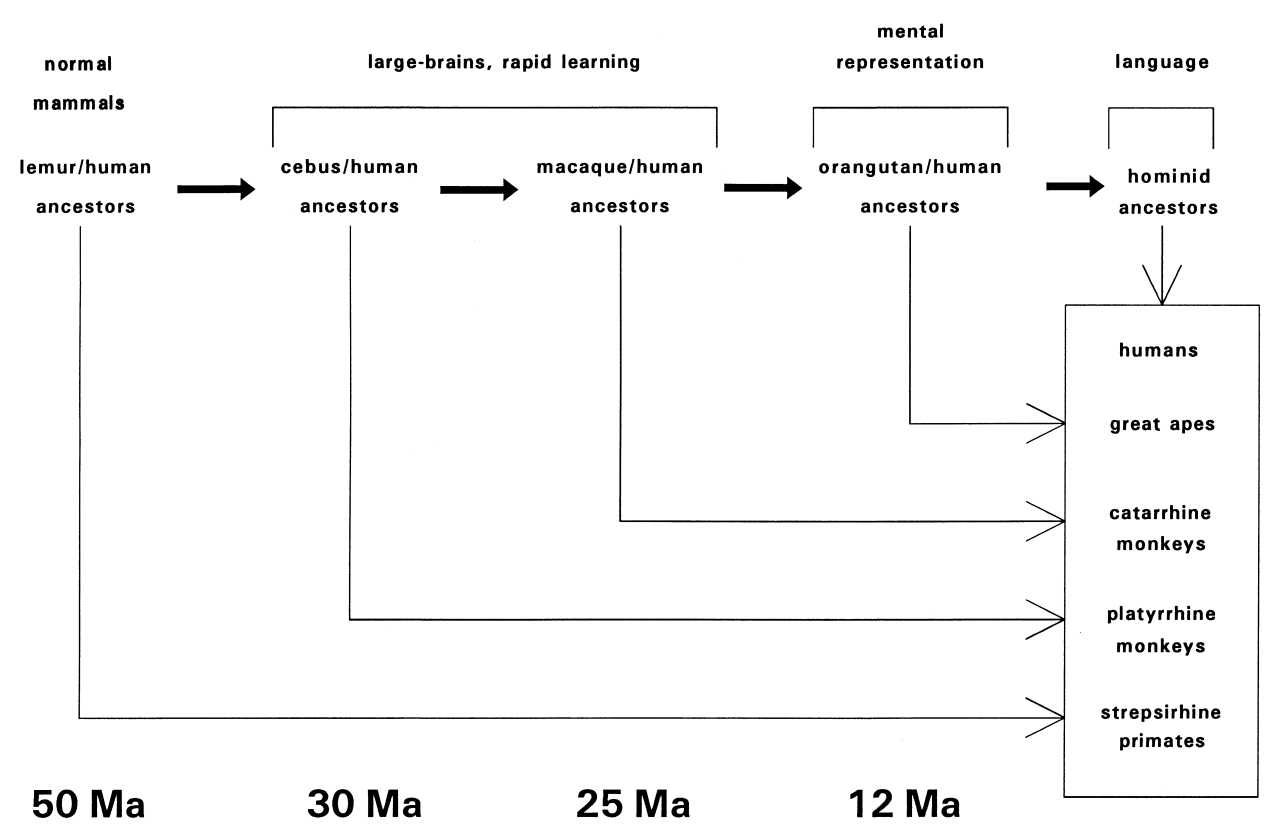

Figure 2. Hypothetical evolutionary path of primate cognition. (See text for explanation.) Note that it is not likely that any of the surviving species are "living fossils" of extinct forms deduced from phylogeny.

However, independent replication of results, improvements in methods, and extension to a greater range of species can be expected to increase the robustness of the somewhat tentative claims made here, and to fill in other gaps in the evolutionary sequence. In order to indicate how the picture I have sketched was actually derived, which of the behavioral data are already robust, and which details may need modification, the next section will give a terse overview of the evidence as it stands at present.

\section{Current Evidence of Primate Cognition}

The primate ancestors. The brains of strepsirhine primates (lemurs and lorises) are no larger in relation to their body mass than those of most other mammalian orders (Passingham, 1981). Most strepsirhines are small animals so that their brains are also small in absolute terms, and even the extinct giant lemurs of Madagascar were very small brained (Forsyth-Major, 1897). Thus the population ancestral to all living primates was not likely to have been specialized for intelligence.

This deduction from morphology is supported by what is currently known of the behavior of strepsirhines. Although some lemurs are group-living, they do not show the differentiation of reaction to different individuals known from monkeys (Cheney \& Seyfarth, 1990b), nor evidence of the use of third-parties in attainment of goals or social dominance (Harcourt \& deWaal, 1992), nor any convincing evidence of tactical deception (Byrne \& Whiten, 1992). In laboratory testing, the few species examined have proved 
much slower at learning than monkeys (Jolly, 1964), and not particularly distinguished in other aspects of cognition (Tomasello \& Call, 1997), although the lack of systematic knowledge makes any conclusion difficult. Given this picture, the conservative assumption is that the cognition of the earliest primates was primitive, that is, not different from most other mammals.

The simian ancestors. In contrast to strepsirhines, simians (monkey and apes) have brains averaging twice the size of a typical mammal of their body mass (Passingham, 1981). Furthermore, many monkeys and all apes are quite large animals, so that the brains of the larger species are also large in absolute terms (Martin, 1990). In laboratory testing, monkeys learn tasks rapidly compared to most mammals tested (Passingham, 1981), and are able to learn category discriminations that depend on comparisons of objects, such as oddity or same-different, unlike other mammals tested (Tomasello \& Call, 1997). Even so, the social sophistication of some large Old World species, revealed in the research of the last 20 years, was unexpected. In these species, rank is strongly a function of social manipulation and support (Chapais, 1992; Datta, 1983b), not only by kin but also by "friends" (Smuts, 1985; Strum, 1983). Supportive relationships are built up by means of social grooming (Dunbar, 1988; Seyfarth \& Cheney, 1984); importantly, because grooming takes time it is an honest indication of the importance of the groomee to the groomer. When key relationships are put at risk by conflict, individuals make efforts to reconcile, and dyads that reconcile are more likely to continue to support each other (Cords, 1997; de Waal \& van Roosmalen, 1979). Various social manipulations have been described, some very subtle (de Waal, 1982), but only tactical deception has been evaluated over a wide range of species (Byrne \& Whiten, 1992). All monkey groups show deception, not simply the larger, Old World species, so the absence in New World monkeys of any use of grooming to build up social support may not reflect any cognitive inferiority. The earliest simians, ancestral to all modern monkeys and apes, were thus likely to have been relatively large-brained animals, living in semipermanent groups in which social sophistication was important to survival.

However, this sophistication may have been based only on rapid learning, rather than any elaborate mental representations. Building up differentiated relationships with many individuals, including keeping a tally of grooming received and whether past help was returned in reciprocated support, does require good memory; it does not seem to require more. To the extent that it has been studied, the ability of monkeys to show real understanding of either the physical world or the mental world of their companions appears highly limited. Tactical deception might in principle give evidence of understanding other minds, but in fact when the data from monkeys were examined, it was concluded that all could be accounted for by very rapid learning, capitalizing on the reinforcement of fortuitously beneficial—but accidental—actions (Byrne, 1997c; Byrne \& Whiten, 1990). Direct tests of monkeys' understanding of other individuals' mental states have proved negative (Cheney \& Seyfarth, 1990a; Povinelli, Parks \& Novak, 1991). Early simians were thus likely to have been quantitatively superior to most other mammals, but not to show any qualitative difference in cognition from them. One prediction to follow 
from this is the that relatively large-brained species within other orders of mammals should similarly prove quick at learning, able to use sophisticated physical skills and social tactics - but only skills and tactics that can be learnt without an understanding of how they work.

The great ape ancestors. Many of the data on social sophistication are clearer in some well-studied monkeys than in any great ape, but it is likely that great apes are similarly able to deploy social tactics and skills. However, in great apes, there are signs of greater understanding of social moves. Furthermore, great apes show more sophisticated interactions with the physical environment than monkeys, and in this domain too give some evidence of real understanding. In most cases, the evidence has first seemed to imply that only one species was capable of a feat, usually the well-studied chimpanzee, but later work has extended this - first to the orangutan and bonobo, and then to the less tractable gorilla. It remains unclear what species differences in cognition among nonhuman great apes are real ones.

In terms of what is seen, differences emerge not in what great apes do-which is in practice often much the same as what monkeys do-but in how they do it. For instance, whereas all observations of tactical deception in monkeys could be plausibly explained as a result of very rapid learning, some of the records from great apes could not, without gross distortion of the meaning of "plausible" (Byrne \& Whiten, 1991). Deception data points to great apes, but not monkeys, having some sort of "theory of mind" about the deceptive intentions and malleable beliefs of other individuals. Deliberate instructional teaching has occasionally been reported in chimpanzees (Boesch, 1991; Fouts, Fouts \& Van Cantford, 1989), but not in any of the equally well-studied monkey species (Caro \& Hauser, 1992). Monkey mothers do regularly encourage their infants' locomotion (Maestripieri, 1995, 1996), and cheetah mothers encourage their infants' hunting and killing skills (Caro, 1994), but it remains possible that these forms of "functional teaching" may not rely on the mothers' understanding their infants' knowledge base, but rather responding on the basis of a genetical adaptation. ${ }^{3}$ Also, individuals of all four great ape species have been taught gestural or ideographic "languages" with some success (see especially Savage-Rumbaugh et al., 1993). This has yet to be attempted with any monkey, but great apes show a flexibility in gestural communication that appears lacking in monkeys: development of the use of novel communicative gestures has been seen in both chimpanzees and gorillas (Tanner \& Byrne, 1996; Tomasello, Call, Nagell, Olguin \& Carpenter, 1994; Tomasello, Gust \& Frost, 1989).

The idea that any nonhuman might possess a theory of mind is a strong claim, and positive evidence has repeatedly been challenged, often with effect; there has been considerable effort devoted to devising a conclusive laboratory test, but none is yet universally agreed. Several of the data initially claimed to show that apes (but not monkeys tested in the same way) can represent the intentions of others have been reinterpreted in other ways. The ability to recognize one's face in a mirror, found in great apes but not in monkeys (Gallup, 1970; Parker, Mitchell \& Boccia, 1994; but see Hauser, Kralik, Botto, Garett \& Oser, 1995), certainly shows that apes have superior cross-modal 
transfer, but perhaps not an ability to understand mental states (Mitchell, 1993). Similarly, the chimpanzee's facility in taking over an untaught role in a two-person cooperative task, compared with macaque monkeys that need to learn the new role from scratch (Povinelli, Nelson \& Boysen, 1992), may be explained as a superior understanding of cause and effect in great apes, without invoking theory of mind (Heyes, 1993). Other tasks more clearly test mental state understanding, but many ape/monkey differences are vulnerable to interpretation as differences in learning speed, if tasks can potentially be learnt over time without mentalistic understanding. (It must be noted that, while in each such experiment the case for theory of mind is thereby rendered "not proven," the data are often more consistent with this interpretation; only the intrinsic improbability and importance of nonhuman theory of mind argues for extreme stringency.)

Some recent tasks offer hope of an agreed resolution, since they remove the fastlearning problem. In one, an individual sees an imminent risk to a close friend or relative (in the laboratory, the most convenient "predator risk" is a veterinarian in white coat!). Conditions differ according to whether the other animal is also able to see the threat, or in a position where its view is obscured. The test individual can clearly see whether or not this is the case, yet macaque monkeys apparently make no distinction, giving just as many alarm calls in both cases (Cheney \& Seyfarth, 1990a). Chimpanzees, however, sharply differentiate, making alarm calls only when they can see their friend is unable to see the threat (Boysen, in preparation). Chimpanzees seem able to distinguish between knowledge and ignorance in other individuals. Another approach centers on the perception of accidental actions. A box containing food is deliberately marked by an experimenter placing a token on top of it (Call \& Tomasello, 1998). However, the experimenter also "accidentally" knocks a token onto another (empty) box, and later "notices the mistake" and with some irritation removes the token; the two boxes remain marked for exactly similar periods of time. Clearly, over many trials, a test animal without any ability to attribute mental states could come to link the communicative signs associated with deliberate marking with gaining a reward, and discriminate those cases from ones where the person acts as if making and correcting an accident. However, in fact neither chimpanzees nor orangutans did increase their discrimination over time, but the exact reverse: their accuracy was highest on trial one and then declined, only later increasing to a moderately high level again. The decline is presumably a response to the oddity of constant "accidents" by the experimenter; the same pattern was shown by people when similarly tested. Chimpanzees and orangutans seem able to discriminate accidents from deliberate, intentional acts.

An ape/monkey difference in cognitive approach may also exist in the way in which they can exploit the physical world. The chimpanzee and the orangutan (van Schaik, Fox \& Sitompul, 1996) are the only primate species regularly to manufacture and use tools for subsistence in the wild, and many tool types have now been described (McGrew, 1992). In captivity, all great apes commonly use and make tools (McGrew, 1989), and the manufacture of stone tools has been induced in orangutans and bonobos (Toth, Schick, Savage-Rumbaugh, Sevcik \& Rumbaugh, 1993; Wright, 1972). In the wild, chimpanzees demonstrate that they possess a mental specification of an appropriate tool when they 
select suitable objects well in advance of the anticipated use as a tool (Boesch \& Boesch, 1984), or deliberately prepare a tool before carrying it to the site of use (Goodall, 1986). No monkeys regularly make or use tools in the wild.

At first, it appeared that the difference lay in the ability to represent the cause and effect relations between tool and task. In captivity, capuchin monkeys will readily learn tool use, and experiments on how they did so suggested deficient understanding (Visalberghi \& Limongelli, 1994; Visalberghi \& Trinca, 1987; Westergaard \& Fragaszy, 1987). Capuchins that had learnt to break nuts with stones and use twigs to extract the kernel, still repeatedly tried to break the nut with blows of the thin twig or used stones to extract kernels, and those that had learnt to use a stick to push a peanut from a tube, when the stick was removed would attempt to get the nut by pushing short sticks in both ends of the tube, or try to probe with chain or a stick to thick to enter the tube. No such errors have been reported in many years of observation of chimpanzee tool-use under natural conditions (Goodall, 1986). However, more recent studies with capuchins have found them able to select and modify sticks according to the necessary properties of an efficient tool (Anderson, 1996; Anderson \& Henneman, 1994). Even tamarin monkeys, which do not normally use tools even in captivity, show an appreciation of which dimensions are relevant to tool function when they choose among proffered objects (Hauser, 1997). It would seem that both monkeys and apes are sensitive to the properties that affect how tools work.

Instead, the difference observed in the wild may derive from social learning mechanisms, and the key aspect of great ape tool-use may be the complexity of their actions, rather than the employment of an object as a tool, per se. Chimpanzee tool use traditions show elaborate structural organization (McGrew, 1992), but so too do the plant processing techniques of mountain gorillas (Byrne \& Byrne, 1991). This raises the possibility of a monkey/ape difference in the complexity of behavioral organization that can be learnt without human intervention. Might great apes have more efficient mechanisms with which to acquire novel skills? Monkeys apparently have great difficulty in imitating the actions of others (Galef, 1988; Visalberghi \& Fragaszy, 1990; Whiten \& Ham, 1992). There is now increasing evidence that great apes can copy novel human actions (Custance, Whiten \& Bard, 1995; Russon \& Galdikas, 1993; Tanner \& Byrne, 1996), although nonhuman great apes lack the very prominent copying of social actions that even very young children show (Meltzoff, 1996, 1988), and the extent to which great apes copy arbitrary actions may be influenced by exposure to humans (Call \& Tomasello, 1996; Tomasello, SavageRumbaugh \& Kruger, 1993). On the other hand, this sort of "action-level" imitation would be of little use for learning complex skills, and its function may be a largely social one (Meltzoff \& Gopnik, 1993).

To learn novel, complex skills by observation, imitation would be needed at a higher level in the hierarchical structure of behavior, the "program-level" (Byrne, 1994; Byrne \& Russon, 1998): the logical organization, including the sequence of actions, bimanual co-ordination and subroutine structure. Byrne \& Russon argue that all great apes show this sort of imitation, based on several different sorts of evidence: in the case of mountain gorillas, population consistency in overall technique, combined with great idiosyncratic 
variation at the level of detail (Byrne \& Byrne, 1993); in the case of orangutans, copying elaborate human traditions of skilled action (Russon, 1996); in the case of chimpanzees, interpopulation differences in tool-using tradition that cannot be explained by ecology (McGrew, Tutin \& Baldwin, 1979). Recent experimentation, based on the model of complex food processing, has found that chimpanzees do tend to copy a demonstrated sequence of actions, an ability that would help enable program-level imitation, but that this imitation depends on repeated observations over trials (Whiten, 1998). If repetition is essential for imitation of this kind (as argued by Russon \& Galdikas, 1995), it becomes less surprising that there exist no compelling field observations of "before/after" differences that show imitation after a single observation of a skilled model.

The underlying cognitive superiority of great apes over monkeys is not easy to pinpoint, but perhaps it can best be described as an ability to form and manipulate representations of instrumental behavior and mental states (Byrne, 1995b, 1997b). Monkeys may prove to be able to represent cause and effect relations among objects, but there is no current evidence that they can acquire complex novel behavior by observation, nor comprehend the intentions that lie behind such behavior. Thus the great ape ancestor would have had a cognitive system qualitatively more like that of humans, able to undertake simple planning and to use others' behavior as a source of knowledge. In relation to body size, great ape brains are no more enlarged on average than those of monkeys (Passingham, 1981), but because all species are large, their brains are of greater mass than those of any other primates. Thus, the cognitive difference may reflect an emergent property of absolute size, or an organizational change in "software" unrelated to volume.

\section{THE EVOLUTIONARY CAUSES OF PRIMATE COGNITION}

\section{Methodology of Inferring Function in Cognitive Evolution}

Exaptation and modularity. The selective pressures that gave rise to primate cognition operated in the distant past; attempting to discover them, we can only observe the design of the resulting adaptations and what functions they have in modern populations. Unfortunately, it is possible for a trait, once evolved, to come to serve an entirely different function (Gould, 1979; indeed, this is the only plausible mechanism for the origin of any adaptations that would fail in partial form to achieve their current function, such as wings too small to fly with.) This so-called "exaptation" is relatively rare, but becomes more likely with adaptations of very general usefulness. Cognitive functions, and especially any based on computation, are thus potentially subject to exaptation. In addition, cognitive mechanisms of very general utility will tend to lack distinctive cues in design. These presumed problems are a consequence of the general-purpose nature of cognition, and yet it has recently been strongly argued that cognition is not in fact general-purpose, but highly modular, consisting of a set of encapsulated "Darwinian algorithms" serving specific functions (Cosmides, 1989; Fodor, 1983). If so, deducing the evolutionary cause of a module's existence should be more straightforward, even obvious. However, the 
degree to which the ancient algorithms postulated for humans work smoothly in the modern world casts doubt on the basic assumption. Exaptation of intelligence does appear routine for at least modern humans, and it seems safer to leave the issue of modularity to empirical enquiry (e.g., Karmiloff-Smith, 1993) rather than assuming that cognitive mechanisms are immune from recruitment to other functions. In consequence, the testing of theories about the selective pressures for cognition (i.e., evolutionary causes) remains a serious problem.

Relating cognitive capacity to natural function. All such theories propose that aspects of cognition arose for dealing efficiently with complexity: perception of structure in a confusing array, selective attention that directs processing and response onto essential aspects of a complex situation, memory for objects and events that have intricate constellations of features, thought processes for solving complex problems and planning in confusing environments, learning to acquire elaborate skills. Theories vary in the domain and nature of the complexity that is hypothesized to have been crucial in favoring cognitive advance. Of course, a cognitive mechanism may be used for many purposes, but only one function is likely to be critical for driving costly evolutionary change at a given time: if the cognitive capacity of an individual were imagined to increase, there must always come a point at which only one function benefits from further increase, and selection will be driven by this function.

In primate work, the usual approach is to assume that current function is a good clue to phylogenetic origin, and compare across species for how a cognitive trait (often as coarsely measured as "brain size") varies with task complexity in different domains or with different measures of complexity. Nonhuman primates can be studied in the field, in environments that probably differ little from those in which adaptation occurred, so treating current function as indicative of phylogenetic origin is a powerful method. One problem is to decide the best unit of comparison: perhaps closely related species are alike, merely by recent common descent, and should be lumped as "one" in analyses? In the past, a conservative approach was taken, analyzing at the genus rather than species level (Clutton-Brock \& Harvey, 1980), but a much better method is now available that uses all the available evidence, contrast analysis (Harvey \& Pagel, 1991). Here, divergence points on the cladogram are taken as the units of analysis: the various measures to be correlated are summed for each of the two branches and compared, and these "contrasts" then constitute independent measures of whether the measures go together in evolution. (If there are $\mathrm{N}$ species, fully resolved into a dichotomous branching cladogram, $\mathrm{N}-1$ contrasts can be obtained.) However, this cannot solve the problem of few species: if there are few contrasts, conclusions must remain speculative.

The selective pressures hypothesized to have favored cognition are usually categorized according to whether complexity in the physical or the social environment is crucial. This distinction is blurred by the case of social learning, in which the complexity may relate to social interactions but the immediate function is to solve physical problems, and I shall treat this separately. Note that most of the theories were originally proposed to explain increased "intelligence," and this vagueness can only sometimes be refined to specific 
aspects of cognition, even now. Furthermore, a theory put forward to explain all intellectual advance may prove valuable in understanding one discrete stage in human and primate ancestry. For these reasons, the various approaches must first be evaluated, before their role (if any) in the historical sequence of Figure 2 can be discerned.

\section{Selection pressures from the Physical Environment}

Tool making. The earliest suggestion of a selective pressure for intelligence must be the venerable idea of "man the tool-maker," dating back at least to Franklin, but put most succinctly and clearly by Oakley (1949). He proposed that bipedalism, in a primate that was already large-brained and manually dextrous enough to make and use tools, set up the circumstances that selected for further increases in intellect and dexterity, because individuals making better tools would be favored. Their descendants would possess larger brains and greater dexterity (with bipedal gait, hand anatomy need no longer be a compromise between manipulation and locomotion), and the same logic would apply, thus setting up positive feedback loops that could in principle cause spiraling increase until brain size and manual control were limited in some way. What aspect of "intelligence" is entailed on this hypothesis is unspecified; tool making could be enhanced by better manual control, better visuospatial imagery, or better understanding of the properties of rocks under percussion. At the time this was proposed, bipedalism appeared to apply among mammals only to the hominid line, and subsequent attempts to find a correlation between increases in brain volume and tool sophistication among hominids have been disappointing (Wynn, 1988). The bipedalism of the earliest hominids, such as Australopithecus afarensis, differed from our own in that many arboreal adaptations were retained, so the hypothesis might not be expected to apply at that stage. However, an extinct European ape of $8 \mathrm{Ma}$, Oreopithecus bambolii, related to the orangutan, has recently been discovered to be bipedal, apparently using its long arms to reach up into vegetation (Köhler \& Moya-Sola, 1997). This provides an interesting sidelight on the centrality of bipedalism, since Oreopithecus was particularly small-brained. Clearly, whether tool-use is important to a species is a function of ecology, so the hypothesis is not completely disproved; however, (plant) tool use is found in some modern orangutans, so to suppose Oreopithecus was not a tool user just because no evidence of (stone) tool use has been found, might be seen as special pleading.

Explanations that depend on bipedalism can only apply to humans among the living primates, but tool use has also been proposed to account for superiority of all great apes over monkeys in representation of object relationships (Parker \& Gibson, 1979). Parker and Gibson's hypothesis was that the great ape ancestors were, like chimpanzees, reliant on tool use for extracting key resources at certain times of year. Because this extractive foraging was seasonal, they argued, an ability to recruit tools to the task was favored, whereas in the closely related gorilla a need to extract plant food was year round, so that a special-purpose morphological adaptation, body size and strength, was instead selected. Testing the rather simpler idea, that extractive foraging per se selects for intelligence, Dunbar (1995) found no correlation among primate species between brain size and use of 
extractive foraging. Testing the theory-as-proposed is beset with problems, because any species that sometimes forages extractively without using tools (and there are many among nonprimate species) can be dismissed as it evidently has appropriate anatomy without a need of tools, and any nonape that relies on tool use for extractive foraging (such as the Californian sea otter) can be dismissed as specialized, because only the chimpanzee uses many types of tools. Additional problems are the fact that gorillas do not in fact rely on brute strength for their extractive foraging (Byrne \& Byrne, 1991; Schaller, 1963), and the awkwardness of assuming obligate tool use in the great ape ancestor, despite the fact that this is found in only two out of five of its descendants. This last is a problem for any account that depends on a behavior found only in one species of nonhuman great ape, when at present all species except for Homo appear rather similar intellectually. Perhaps for this reason, the complexity involved in co-operative hunting has seldom been proposed to underlie ape intelligence: among primates, hunting of large, active animals has only been recorded in chimpanzees. (The much greater cooperation implied by effective hunting of big game has of course been suggested to underlie more advanced intelligence in Homo.)

Spatial knowledge. A selection pressure that could apply to a much wider range of primates was originally suggested on the basis of anecdotal observations of the large ranges of orangutans and spider monkeys, both rather large-brained species, and the animals' apparent excellent knowledge of them (Mackinnon, 1978; Milton, 1981). The idea is that if a species is adapted to forage on diet items that are sparsely and patchily distributed, and vary predictably with the complex seasonality of tropical forests, then any extra processing capacity that enables prediction of when and where to forage would be favored. Here, brain size increase is a matter of better memory. This has been tested for a large number of primate species by comparing range area, and degree of frugivory, with brain size relative to body size (Clutton-Brock \& Harvey, 1980). Frugivorous primates would benefit from knowing the locations and fruiting of many different individuals of many species of tree, folivorous species can survive on widely available leaves; thus, it is argued, good memory is advantageous to frugivores, in rough proportion to the size of their home range. (Note that frugivory is also thought to underlie evolution of trichromatic color vision (Jacobs, 1994), on the basis that it aids detection of fruit and assessment of ripeness.) With both range area and frugivory, the correlation with brain size was positive; this result was found separately for simians and strepsirhines, but the latter lay on a different regression since their brains are smaller for a given body size. As well as accounting for the relative brain sizes among simians and among strepsirhines, this theory can explain the generally smaller brains of strepsirhine primates, because their morphology is strongly biased towards folivory compared to simians of the same size even in species that preferentially eat fruit or insects.

However, the idea that brain size relative to body size is an appropriate index of cognitive capacity has been challenged (Byrne, 1994, 1996). Relative brain size is a good indication of the strength of the selection pressure promoting intelligence, because large brains are so costly, but may be a poor index of what cognitive activity the brain allows. 
If the brain is an "on-board computer," then like any computing machine it must be limited by the number of its components, and if the primate brain is not acting as a computing machine then the fundamental premise of selection for cognitive function is violated. Thus absolute size is the proper measure of cognitive power, while relative size remains useful as a measure of the cost the species is currently bearing as a result of recent selection for absolute brain size. Of course, maintenance of bodily functions will also demand some brain capacity, and this will increase with body size, cutting in to the brain capacity available for underwriting intelligent behavior. This complication will be most problematic in small-brained species, less so in primates where much of the brain volume is associated with secondary motor and perceptual processing of direct relevance to intelligence.

Instead of reflecting selection for good memory, the strong correlations between relative brain size, range area and diet type may be artifacts of gut size. More folivorous species can manage with smaller ranges, and at the same time have larger guts, and hence larger bodies; thus the correlation of relative brain size and range area can emerge as a result of selection on body size rather than brain size (Deacon, 1990; Shea, 1983). (Also, because gut tissue is next to brain tissue in metabolic demand (Aiello \& Wheeler, 1995), there is an additional pressure for species that need large guts, such as folivores, to minimize brain size.) Range area inevitably correlates with body size, but when residuals of range area in this regression are compared to absolute brain size, or to neocortex volume in proportion to the rest of the brain, no correlations emerge (Barton \& Purvis, 1994; Dunbar, 1992). However, primary visual cortex is larger in diurnal simians, especially frugivores (Barton, Purvis \& Harvey, 1995), and within diurnal simians it correlates with frugivory (Barton, 1996), an effect which makes a small contribution to overall brain size, and that Barton interprets as selection on basic mechanisms of locating and selecting fruit.

Arboreal locomotion. Theories that link cognitive evolution to environmental complexity are normally couched in terms of increasing memory capacity or learning efficiency. However, one ingenious suggestion attempts to relate mental state representation directly to a physical requirement in ape ancestry. This is the idea that, for a heavy ape, the problem of safely clambering through a canopy of fragile vines and branches may have selected for an ability to treat the self as an objective entity, accounting for all great apes' ability to interpret their reflection as being themselves (Povinelli \& Cant, 1995). Once the self is "objectified," the way is open for treating other individuals as like the self, with knowledge and intentions (Gallup, 1982). This could explain the origin of the close correlation between mirror self-recognition and mental state attribution in great apes and children (Gallup, 1982; Whiten \& Byrne, 1991), but it is unclear how the idea may be tested further.

\section{Selection Pressures from the Social Environment}

Machiavellian intelligence. For a social primate, the environment includes also its social companions, individuals that have large or complete overlap in their requirements 
for resources. Evidently social living is ultimately beneficial to them, most likely in reducing predation risk (van Schaik, 1983), but it brings with it major problems of competition. Perhaps dealing efficiently with the problems posed by social companions was the principal selective pressure for primate intelligence? Various points have been used to argue that it was, under the rubric of "Machiavellian intelligence" (Byrne \& Whiten, 1988), because in all cases the benefits to the individual lie in social manipulation. These include:

- The inherent fluidity and reactivity of conspecifics poses a special challenge (Chance \& Mead, 1953), compared to the more static complexity of the physical world.

- Predator/prey systems share the need to compute the changing actions of other individuals, but an individual's social competitors inevitably have essentially the same intelligence as itself, giving a "ratchet" effect of any increase in reproductive success that results from one individual's superior intelligence, because this will automatically increase the average intelligence of the next generation (Humphrey, 1976).

- In the socially unsophisticated lemurs, there is also relatively little sign of practical intelligence; thus sociality might lead to intelligence, but not vice versa (Jolly, 1966).

- Despite an apparent absence of any significant intellectual problems in the physical environment of some species, such as the gorilla, they nevertheless show remarkable intelligence (Humphrey, 1976).

- In general, the many cognitive achievements of monkeys and apes are remarkably impressive (Byrne \& Whiten, 1988; de Waal, 1982; Kummer, 1982), compared with the much weaker evidence of their knowledge about natural history (Cheney \& Seyfarth, 1988). It has even been suggested that this legacy of cognitive advance in social matters causes humans to interpret physical systems as if they were active social agents (Humphrey, 1976), with disastrous or amusing consequences.

However, although data on the social complexity of primates increase the plausibility of some form of social pressure for intelligence, in no sense do they test the hypothesis. To determine how best to do so, it is necessary to be more specific about what is involved. Several aspects of cognition have been invoked as components of Machiavellian intelligence (Byrne, 1997a). Discrimination of individual identity and emotional state depends on face processing systems which have often been suggested to be cognitively complex, in humans and other primates (Brothers, 1990; Perrett et al., 1989). The characteristics of individuals pose a memory challenge, which increases linearly with group size if only immediate relationships with the self are remembered, but geometrically if relationships between third parties are also noted (Whiten \& Byrne, 1988), and there is evidence that monkeys do indeed take account of kin associations and dominance relationships between third parties (Cheney, Seyfarth \& Smuts, 1986). Primates also remember individuals' past histories of group residence (Cheney \& Seyfarth, 1982), their initiation of and pattern of support in aggression (Datta, 1983a) and friendships with others (Smuts, 1983; Strum, 1983), individuals' value in co-operation, including past reciprocation of help and failures to reciprocate (Packer, 1977), and tendencies to be predictable or inconsistent, for instance 
their reliability as a source of information (Cheney \& Seyfarth, 1990b). It is clear that the potential memory load needed to profit individually in a social environment is very large. Using this information to learn social tactics, such as deception, from coincidental conjunctions of events that happen rarely, may require particularly rapid learning, and integration of several items in working memory at the same time (Byrne, 1997c): cats and dogs are able to acquire similar tactics in captivity, when the necessary coincidences are more frequent, but in the wild this has yet to be properly documented even in the large-brained social carnivores. Taking account of the presence and actions of third parties in aggressive encounters, or in co-operative prey capture (Boesch, 1994; Teleki, 1973), may also require substantial immediate memory capacity. Thus far, all the indications of social complexity may rely only on rapid learning and extensive memory for individuals and their traits; however, some sort of problem-solving may also be involved, in the mental simulation of the likely future behavior of competitors or maneuvers that could outwit them (Byrne, 1995a). In principle this could even involve mental state attribution or "theory of mind" (Premack \& Woodruff, 1978).

Direct testing of social hypotheses has centered on the use of neocortical ratios as an index of brain enlargement in the primate lineage, because the neocortex is responsible for most of the variation among primates (Stephan, Frahm \& Baron, 1981). Average group size, as a rough measure of the social "problem" an individual confronts, correlates with neocortex ratio in simian primates, both across species and across phylogenetic contrasts (Barton, 1996; Dunbar, 1992). This effect is not restricted to primates, applying also to carnivores and dolphins, and in insectivorous bats those species with stable social groups have larger neocortex ratio (Barton \& Dunbar, 1997; Marino, 1996). Group size is only an indirect measure of social complexity, but a direct relationship between brain enlargement and behavioral complexity in social circumstances has also been found. Neocortex ratio predicts the amount of tactical deception that is reported for a primate taxon, when amount of effort invested in field study is controlled (Byrne, 1993, 1996). And larger neocortex ratio seems to pay off in an interesting way: male rank is less closely related to mating success in species with larger neocortical ratio, suggesting perhaps that the gains of brute force can be undermined by strategy (Pawlowski, Lowen \& Dunbar, 1998).

However, an ape/monkey difference in cognition cannot be explained by neocortical ratios, which overlap between the taxa, and the social group size of monkeys and apes also overlap completely, so the Machiavellian intelligence hypothesis would give no explanation of great ape cognitive superiority (Byrne, 1997b). The correlations between brain enlargement, social group size, and a kind of social manipulation - tactical deceptionthat does not require understanding of mental states, suggests that the selective pressure of social complexity may result in larger brains that allow rapid learning on the basis of elaborate social knowledge, but not necessarily any deep, representational understanding of mechanism.

Social solutions to environmental problems. Living socially presents opportunities as well as problems, because the knowledge of other individuals may be useful. In principle, this knowledge can be gained without individual experimentation, by means of social 
learning, and the long periods of dependency of monkeys and especially apes have been seen as potential "apprenticeships" enabling acquisition of skills for dealing with physical problems (Bruner, 1972; Parker, 1996). Social enhancement of learning is well known in many species (Galef, 1988; Spence, 1937), whereas the direct acquisition of others' knowledge by imitation has been difficult to establish even among great apes, and is apparently absent in monkeys and strepsirhines. However, the recent evidence that suggests that great apes can imitate the "program level" of organization of complex behavior, understanding hierarchical organization and thus constructing novel plans partly by observation, raises a new problem: how did the ability to mentally represent the organization of complex behavior evolve?

There are at least two possible ways in which natural selection might have favored an ability to structure actions hierarchically, and thus given rise to an ability to perceive structure in the behavior of others and so learn their skills by imitation (Byrne, 1997b). Large body size and the high energetic cost of brachiation during long-range travel makes efficient feeding a priority for living great apes. This need is sharpened by competition from Old World monkeys, species which occur throughout the geographical range of great apes and are able to eat fruits when less ripe and leaves when tougher, than can apes. Great apes clearly must have some competitive advantage, to survive at all. All great ape species build nests, rather elaborate constructions of living branches that enable them to sleep in a wide range of sites; the advantage this gives in enabling them to sleep near food has been suggested to have selected for mechanical construction skill (Fruth \& Hohmann, 1996). Alternatively, the need to process foods with greater efficiency, enabling access to physically defended plants and insects unavailable to monkeys, has been proposed to have selected directly for skilled manual learning (Byrne, 1997b). These hypotheses are recent, and have yet to be tested systematically.

\section{CONCLUSIONS}

From what has been reviewed, it should be clear that the most obvious conclusion is that, as yet, no firm conclusions about the evolution of primate cognition are wise. Nevertheless, I will suggest a possible scenario, based on the methods of evolutionary reconstruction outlined in this paper, and treating the tentative conclusions summarized in Figure 2 as correct. This is put forward in the spirit of offering an edifice on which to hang current data, one which may tempt researchers to attempt its demolition-with the result that in time a more secure structure can be created.

The early primates before $50 \mathrm{Ma}$ were rather small, largely insectivorous, nocturnal animals. Those few larger species that did exist ate a wide range of plant and animal food, but were able to fall back on a rather coarse plant diet, available year-round in a relatively small range. Their brain sizes were relatively small, either because of generally small body size, or in larger species because metabolic constraints of their diet set an upper limit on brain size. Cognitively, these primates differed little from most other mammals existing at that time, or since. 
At some time before $30 \mathrm{Ma}$, one population of primates was subject to a strong selection pressure for greater learning abilities, necessitating enlargement of parts of neocortex involved in social information processing. This pressure derived from an environment of increased social complexity in these ancestral simians, caused by living in semipermanent groups. Group living was most likely a response to increased predation, perhaps itself a result of a diurnal lifestyle. Brain enlargement brought increased metabolic costs, met in part by an increase in body sizes but also necessitating a relative increase in brain size as a proportion of the body. This required a diet shift towards higher energy foods, principally ripe fruit, and thus larger home ranges, since sources of ripe fruit are ephemeral. Diurnal frugivory, in addition, selected for trichromatic color vision and a corresponding increase in primary visual cortex. These early simian primates were therefore highly visual animals, able to learn rapidly, and with elaborate social knowledge. Whether or not as a direct result of social complexity, they could also form concepts based on comparisons of characteristics, and had some understanding of the relationship between the properties and functions of objects.

Among the highly social, relatively large-brained descendants of these early simians, at some time between $25 \mathrm{Ma}$ and $12 \mathrm{Ma}$, one population adapted in response to a very different selection pressure. This population was ancestral to modern great apes, and distinguished by locomotor adaptations towards arboreal clambering and swinging. The selection pressure seems likely to have been in some way a consequence of the inefficiency of apes in quadrupedal walking, in conjunction with their need to obtain a relatively high energy diet-in competition with other species, including monkeys with more efficient digestive adaptations. We know from fossil evidence that most ape species did in fact become extinct, but the one species that gave rise to all surviving forms-including humans - acquired an ability to understand and to perceive the hierarchical structure of behavior, to represent cause and effect relationships, and to manipulate them in simple planning. The immediate benefits of these abilities were in acquiring elaborate manual skills by individual construction and social learning, enabling more efficient food processing, or allowing nest building and hence preferential access to food. The secondary consequence was that mental states, as well as physical descriptions, could be represented, causing a great increase in the subtlety of social lives of these animals, though few overt differences in social behavior. Furthermore, the ability to represent the knowledge of other individuals was an essential precursor for the evolution of true communication in one group of their descendants, the hominids.

Like any evolutionary account, this is a story, albeit one that is consistent with many of the known facts about the surviving descendants of the evolutionary events known to have taken place from phylogenetic evidence. However, its accuracy is entirely dependent on the data available, and there are three different types of problem inherent in current data:

1. The fragility of negative evidence. Inevitably, pinpointing when in evolution capacities first evolved, the data amounts to the finding that some species have the capacity, whereas their nearest relatives, and their more primitive relatives, do not. The key to this is the nearest relatives who do not show the ability: thus, every claim rests on individuals 
of some species of animal regularly failing in an experimental task, or never having been observed showing a diagnostic behavior in the wild. These types of negative evidence are fragile. Tomorrow, a new population may be discovered that regularly shows the behavior, or a redesigned experiment may allow individuals to show the capacity which poorer designs masked: skilled tool use in orangutans (Fox, Sitompul \& Van Schaik, 1999), and mirror self-recognition in gorillas (Patterson \& Cohn, 1994) are illustrative cases.

2. Unrepresentative samples of species. It will have become obvious that the wellstudied, relatively large, diurnal, semiterrestrial species of primate, and the great apes, are over-represented in the data available at present (see Figure 1, which includes all genera mentioned by name in this paper). This is unremarkable in one sense, because it is very much harder to obtain quality data on small, highly arboreal species, let alone nocturnal ones, and a particular focus on our closest relatives is reasonable. However, there may be surprises in store when a broader range of monkey and strepsirhine species are studied, and in any case the more separate branches of the primate tree are studied, the more contrasts are available for testing theories of which selection pressure led to which cognitive adaptation. The species which fail to show some aspect of cognition are just as important in reconstructing evolution as those "more glamorous" ones that show human traits.

3. Unresolved controversies. Many areas of animal cognition are controversial: in general, I have unashamedly selected the data and conclusions that I believe correct, although I have usually mentioned or even discussed the disagreement (e.g., the case of whether monkeys understand the properties of a tool). However, one very recent report that runs so counter to the bulk of the evidence, and if confirmed would mean a major change in evolutionary interpretation, concerns the use of the habituation-dishabituation paradigm to present the "Sally-Ann" task to tamarin monkeys (Hauser \& Santos, 1998). Tamarins looked longer in precisely those conditions in which the (human) actor violated the expectations of an observer with theory of mind. Whether this shows that tamarins have theory of mind, or that the task is less diagnostic than had been thought, it is liable to lead to revision of several current positions.

Rather than an attempt at a final synthesis, the account I have given of the historical sequence and causal forces that led to the cognition of the last common ancestor we share with any animal should be seen as a challenge. If it serves to energize future research that shows it to be flawed in numerous ways, it will have done its job.

Acknowledgments: I would like to thank those who read the first draft and gave me their helpful advice: James Greeno, Steven Mithen, Michael Tomasello, and an anonymous referee. This paper has benefited greatly from their efforts, but mistakes which remain are my own responsibility alone.

\section{NOTES}

1. Now that a portion of the Neanderthal genome has been reconstructed (Krings et al., 1997) we can hope to discover whether the Neanderthals, known from abundant fossil material and thousands of stone tools, had 
a direct genetic input into modern humanity. This may never be possible for other extinct hominids; recent media claims that Homo erectus contributed directly to modern human genes are hard to evaluate, when there is no way in principle of recognizing erectus genetic material.

2. The potentiating circumstances are normally called the selective "pressure," and the resulting characteristic is often described as "for" a particular purpose; but it must always be remembered that the pressure is entirely passive, and that however teleological its products may appear to be, evolution is not a goaldirected process.

3. In fact, Whiten (Whiten, 1999) has argued that a case in which a mother gorilla in a zoo did just the same has greater significance, because gorillas in the wild have not been seen to do so.

\section{REFERENCES}

Aiello, L., \& Wheeler, P. (1995). The expensive tissue hypothesis. Current Anthropology, 36, 199-221.

Aiello, L. C., \& Dunbar, R. I. M. (1993). Neocortex size, group size and the evolution of language. Current Anthropology, 34, 184-193.

Anderson, J. R. (1996). Chimpanzees and capuchin monkeys: comparative cognition. In A. E. Russon, K. A. Bard, \& S. T. Parker (Eds.), Reaching into thought: The minds of the great apes (pp. 23-56). Cambridge: Cambridge University Press.

Anderson, J. R., \& Henneman, M. C. (1994). Solutions to a tool-use problem in a pair of Cebus apella. Mammalia, 58, 351-361.

Armstrong, E. (1983). Relative brain size and metabolism in mammals. Science, 220, 1302-1304.

Barkow, J. H., Cosmides, L., \& Tooby, J. (Eds.). (1992). The adapted mind: Evolutionary psychology and the generation of culture. Oxford: Oxford University Press.

Barton, R., \& Dunbar, R. I. M. (1997). Evolution of the social brain. In A. Whiten \& R. W. Byrne (Eds.), Machiavellian intelligence II: Extensions and evaluations (pp. 240-263). Cambridge: Cambridge University Press.

Barton, R., \& Purvis, A. (1994). Primate brains and ecology: Looking beneath the surface. In J. R. Anderson, J. J. Roeder, B. Thierry, \& N. Herrenschmidt (Eds.), Proceedings of the 14th Congress of the International Primatological Society. Strasbourg: Université Louis Pasteur.

Barton, R. A. (1996). Neocortex size and behavioural ecology in primates. Proceedings of the Royal Society, B, 263, 173-177.

Barton, R. A., Purvis, A., \& Harvey, P. H. (1995). Evolutionary radiation of visual and olfactory brain systems in primates, bats and insectivores. Philosophical Transactions of the Royal Society, B, 348, 381-392.

Boesch, C. (1991). Teaching among wild chimpanzees. Animal Behaviour, 41, 530-532.

Boesch, C. (1994). Cooperative hunting in wild chimpanzees. Animal Behaviour, 48, 653-667.

Boesch, C., \& Boesch, H. (1984). Mental map in wild chimpanzees: an analysis of hammer transports for nut cracking. Primates, 25, 160-170.

Brothers, L. (1990). The social brain: A project for integrating primate behavior and neurophysiology in a new domain. Concepts in Neuroscience, 1, 27-51.

Bruner, J. S. (1972). Nature and uses of immaturity. American Psychologist, 27, 687-708.

Buss, D. M. (1989). Sex differences in human mate preferences: Evolutionary hypotheses tested in 37 cultures. Behavioral and Brain Sciences, 12, 1-49.

Byrne, R. W. (1993). Do larger brains mean greater intelligence? Behavioral and Brain Sciences, 16, 696-697.

Byrne, R. W. (1994). The evolution of intelligence. In P. J. B. Slater \& T. R. Halliday (Eds.), Behaviour and evolution (pp. 223-265). Cambridge: Cambridge University Press.

Byrne, R. W. (1995a). The ape legacy: The evolution of Machiavellian intelligence and interactive planning. In E. N. Goody (Ed.), Social intelligence and interaction (pp. 37-52). Cambridge: Cambridge University Press.

Byrne, R. W. (1995b). The thinking ape: Evolutionary origins of intelligence. Oxford: Oxford University Press.

Byrne, R. W. (1996). Relating brain size to intelligence in primates. In P. A. Mellars \& K. R. Gibson (Eds.), Modelling the early human mind (pp. 49-56). Cambridge: Macdonald Institute for Archaeological Research.

Byrne, R. W. (1997a). Machiavellian intelligence. Evolutionary Anthropology, 5, 172-180.

Byrne, R. W. (1997b). The technical intelligence hypothesis: An additional evolutionary stimulus to intelligence? In A. Whiten \& R. W. Byrne (Eds.), Machiavellian intelligence II: Extensions and evaluations (pp. 289-311). Cambridge: Cambridge University Press. 
Byrne, R. W. (1997c). What's the use of anecdotes? Attempts to distinguish psychological mechanisms in primate tactical deception. In R. W. Mitchell, N. S. Thompson, \& L. Miles (Eds.), Anthropomorphism, anecdotes, and animals: The emperor's new clothes? (pp. 134-150). New York: SUNY Press Biology and Philosophy.

Byrne, R. W., \& Byrne, J. M. E. (1991). Hand preferences in the skilled gathering tasks of mountain gorillas (Gorilla g. beringei). Cortex, 27, 521-546.

Byrne, R. W., \& Byrne, J. M. E. (1993). Complex leaf-gathering skills of mountain gorillas (Gorilla g. beringei): Variability and standarization. American Journal of Primatology, 31, 241-261.

Byrne, R. W., \& Russon, A. (1998). Learning by imitation: a hierarchical approach. Behavioral and Brain Sciences, 21, 667-721.

Byrne, R. W., \& Whiten, A. (1988). Machiavellian intelligence: Social expertise and the evolution of intellect in monkeys, apes and humans. Oxford: Clarendon Press.

Byrne, R. W., \& Whiten, A. (1990). Tactical deception in primates: The 1990 data-base. Primate Report, 27, $1-101$.

Byrne, R. W., \& Whiten, A. (1991). Computation and mindreading in primate tactical deception. In A. Whiten (Ed.), Natural theories of mind (pp. 127-141). Oxford: Basil Blackwell.

Byrne, R. W., \& Whiten, A. W. (1992). Cognitive evolution in primates: Evidence from tactical deception. Man, 27, 609-627.

Call, J., \& Tomasello, M. (1996). The effect of humans on the cognitive development of apes. In A. Russon, K. Bard, \& S. Parker (Eds.), Reaching into thought: The minds of the great apes (pp. 371-403). Cambridge: Cambridge University Press.

Call, J., \& Tomasello, M. (1998). Distinguishing intentional from accidental actions in orangutans (Pongo pygmaeus), chimpanzees (Pan troglodytes), and human children (Homo sapiens). Journal of Comparative Psychology, 112, 192-206.

Caro, T. M. (1994). Cheetahs of the Serengeti plains: Grouping in an asocial species. Chicago: University of Chicago Press.

Caro, T. M., \& Hauser, M. D. (1992). Is there teaching in non-human animals? Quarterly Review of Biology, 67, 151-174.

Chance, M. R. A., \& Mead, A. P. (1953). Social behaviour and primate evolution. Symposia of the Society of Experimental Biology, 7, 395-439.

Chapais, B. (1992). The role of alliances in social inheritance of rank among female primates. In A. H. Harcourt \& F. B. M. de Waal (Eds.), Coalitions and alliances in humans and other primates (pp. 29-59). Oxford: Oxford University Press.

Cheney, D. L., \& Seyfarth, R. M. (1982). Recognition of individuals within and between groups of free-ranging vervet monkeys. American Zoologist, 22, 519-529.

Cheney, D. L., \& Seyfarth, R. M. (1988). Social and non-social knowledge in vervet monkeys. In R. W. Byrne \& A. Whiten (Eds.), Machiavellian intelligence: Social expertise and the evolution of intellect in monkeys, apes and humans (pp. 255-270). Oxford: Clarendon Press.

Cheney, D. L., \& Seyfarth, R. M. (1990a). Attending to behaviour versus attending to knowledge: examining monkeys' attribution of mental states. Animal Behaviour, 40, 742-753.

Cheney, D. L., \& Seyfarth, R. M. (1990b). How monkeys see the world: Inside the mind of another species. Chicago: University of Chicago Press.

Cheney, D. L., Seyfarth, R. M., \& Smuts, B. B. (1986). Social relationships and social cognition in nonhuman primates. Science, 234, 1361-1366.

Clutton-Brock, T. H., \& Harvey, P. H. (1980). Primates, brains and ecology. Journal of Zoology, London, 190, 309-323.

Cords, M. (1997). Friendships, alliances, reciprocity and repair. In A. Whiten \& R. W. Byrne (Eds.), Machiavellian intelligence II: Extensions and evaluations (pp. 24-49). Cambridge: Cambridge University Press.

Cosmides, L. (1989). The logic of social exchange: Has natural selection shaped how humans reason? Studies with the Wason selection task. Cognition, 31, 187-276.

Custance, D. M., Whiten, A., \& Bard, K. A. (1995). Can young chimpanzees (Pan troglodytes) imitate arbitrary actions? Hayes \& Hayes (1952) revisited. Behaviour, 132, 11-12.

Daly, M., \& Wilson, M. (1990). Killing the competition. Human Nature, 1, 83-109.

Daly, M., \& Wilson, M. I. (1996). Violence against stepchildren. American Psychological Society, 77-81. 
Datta, S. B. (1983a). Patterns of agonistic interference. In R. A. Hinde (Ed.), Primate social relationships: An integrated approach (pp. 289-297). Oxford: Blackwell.

Datta, S. B. (1983b). Relative power and the acquisition of rank. In R. A. Hinde (Ed.), Primate social relationships: An integrated approach (pp. 93-103). Oxford: Blackwell.

Dawkins, R. (1986). The blind watchmaker. London \& New York: Longman.

de Waal, F. (1982). Chimpanzee politics. London: Jonathan Cape.

de Waal, F., \& van Roosmalen, A. (1979). Reconciliation and consolation among chimpanzees. Behavioral Ecology and Sociobiology, 5, 55-56.

Deacon, T. W. (1990). Fallacies of progression in theories of brain-size evolution. International Journal of Primatology, 11, 193-236.

Dunbar, R. I. M. (1988). Primate social systems. London: Croom Helm.

Dunbar, R. I. M. (1992). Neocortex size as a constraint on group size in primates. Journal of Human Evolution, 20, 469-493.

Dunbar, R. I. M. (1995). Neocortex size and group size in primates: A test of the hypothesis. Journal of Human Evolution, 28, 287-296.

Fodor, J. A. (1983). The modularity of mind. Cambridge MA: MIT Press.

Foley, R. (1996). The adaptive legacy of human evolution: A search for the the environment of evolutionary adaptedness. Evolutionary Anthropology, 4, 194-203.

Forsyth-Major, C. I. (1897). Proceedings of the Royal Society, 62, 46-50.

Fouts, R. S., Fouts, D. H., \& Van Cantford, T. E. (1989). The infant Loulis learns signs from cross-fostered chimpanzees. In R. A. Gardner, B. T. Gardner, \& T. E. Van Cantford (Eds.), Teaching sign language to chimpanzees (pp. 280-292). New York: State University of New York Press.

Fox, E., Sitompul, A., \& Van Schaik, C. P. (1999). Intelligent tool use in wild Sumatran orangutans. In S. T. Parker, H. L. Miles, \& R. W. Mitchell (Eds.), The mentality of gorillas and orangutans (pp. 99-116). Cambridge: Cambridge University Press.

Fruth, B., \& Hohmann, G. (1996). Nest building behavior in the great apes. In W. C. McGrew, L. F. Marchant, \& T. Nishida (Eds.), Great ape societies (pp. 225-240). Cambridge: Cambridge University Press.

Galef, B. G. (1988). Imitation in animals: History, definitions, and interpretation of data from the psychological laboratory. In T. Zentall \& B. G. Galef, Jnr. (Eds.), Social learning: Psychological and biological perspectives (pp. 3-28). Hillsdale, New Jersey: Erlbaum.

Gallup, G. G., Jnr. (1970). Chimpanzees: self-recognition. Science, 167, 86-87.

Gallup, G. G., Jnr. (1982). Self-awareness and the emergence of mind in primates. American Journal of Primatology, 2, 237-248.

Goodall, J. (1986). The chimpanzees of Gombe: Patterns of behavior. Cambridge, MA: Harvard University Press.

Goodman, M., Bailey, W. J., Hayasaka, K., Stanhope, M. J., Slightom, J., \& Czelusniak, J. (1994). Molecular evidence on primate phylogeny from DNA sequences. American Journal of Physical Anthropology, 94, $3-24$.

Gould, S. J. (1979). The spandrels of San Marco and the Panglossian paradigm: a critique of the adaptationist programme. Proceedings of the Royal Society, B, 205, 581-598.

Harcourt, A. H., \& de Waal, F. B. (Eds.). (1992). Coalitions and alliances in humans and other animals. Oxford: Oxford University Press.

Harvey, P. H., \& Clutton-Brock, T. H. (1985). Life history variation in primates. Evolution, 39, 559-581.

Harvey, P. H., \& Pagel, M. (1991). The comparative method in evolutionary biology. Oxford: Oxford University Press.

Hauser, M. (1997). Artifactual kinds and functional design features: what a primate understands without language. Cognition, 64, 285-308.

Hauser, M. D., Kralik, J., Botto, C., Garett, M., \& Oser, J. (1995). Self-recognition in primates: Phylogeny and the salience of species-typical traits. Proceedings of the National Academy of Sciences, 92, 10811-10814.

Hauser, M. D., \& Santos, L. (1998). Monkey mentalists or behaviorists? Results from a false belief test. Paper presented at the XVIIth Congress of the International Primatological Society, August 10-14, University of Antananarivo, Madagascar.

Hennig, W. (1966). Phylogenetic systematics. Urbana: Illinois Press.

Heyes, C. M. (1993). Anecdotes, training, trapping and triangulating: do animals attribute mental states? Animal Behaviour, 46, 177-188. 
Humphrey, N. K. (1976). The social function of intellect. In P. P. G. Bateson \& R. A. Hinde (Eds.), Growing points in ethology (pp. 303-317). Cambridge, England: Cambridge University Press.

Jacobs, G. H. (1994). Variations in primate colour vision: Mechanisms and utility. Evolutionary Anthropology, 3, 196-205.

Jerison, H. J. (1973). Evolution of the brain and intelligence. New York: Academic Press.

Jolly, A. (1964). Prosimians' manipulation of simple object problems. Animal Behaviour, 12, 560-571.

Jolly, A. (1966). Lemur social behaviour and primate intelligence. Science, 153, 501-506.

Jones, S., Martin, R. D., \& Pilbeam, D. (Eds.). (1992). The Cambridge encyclopaedia of human evolution. Cambridge: Cambridge University Press.

Karmiloff-Smith, A. (1993). Beyond modularity: A developmental perspective on cognitive science. Massachusetts: Bradford/M.I.T.

Kim, H.-S., \& Takenaka, O. (1996). A comparison of TSPY genes from Y chromosomal DNA of the great apes and humans: Sequence, evolution, and phylogeny. American Journal of Physical Anthropology, 100, 301-309.

Köhler, M., \& Moya-Sola, S. (1997). Ape-like or hominid-like? The positional behavior of Oreopithecus bambolii reconsidered. Proceedings of the National Academy of Sciences, 94, 11747-11750.

Krings, M., Stone, A., Schmitz, R. W., Krainitzki, H., Stoneking, M., \& Paabo, S. (1997). Neanderthal DNA sequences and the origin of modern humans. Cell, 90, 19-30.

Kummer, H. (1982). Social knowledge in free-ranging primates. In D. R. Griffin (Ed.), Animal mind_human mind. New York: Springer-Verlag.

Mackinnon, J. (1978). The ape within us. London: Collins.

Maestripieri, D. (1995). First steps in the macaque world: Do rhesus mothers encourage their infants independent locomotion? Animal Behaviour, 49, 1541-1549.

Maestripieri, D. (1996). Maternal encouragement of infant locomotion in pigtail macaques. Animal Behaviour, $51,603-610$.

Marino, L. (1996). What can dolphins tell us about primate evolution? Evolutionary Anthropology, 5, 81-85.

Martin, R. D. (1990). Primate origins and evolution. London: Chapman Hall.

McGrew, W. C. (1989). Why is ape tool use so confusing? In V. Standen \& R. A. Foley (Eds.), Comparative socioecology: The behavioural ecology of humans and other mammals (pp. 457-472). Oxford: Blackwell Scientific Publications.

McGrew, W. C. (1992). Chimpanzee material culture: Implications for human evolution. Cambridge: Cambridge University Press.

McGrew, W. C., Tutin, C. E. G., \& Baldwin, P. J. (1979). Chimpanzees, tools and termites: cross-cultural comparison of Senegal, Tanzania and Rio Muni. Man, 14, 185-214.

Mellars, P. A., \& Stringer, C. (Eds.). (1989). The human revolution: Behavioural and biological perspectives on the origins of modern humans. Princeton, NJ: Princeton University Press.

Meltzoff, A. (1996). The human infant as imitative generalist: A 20-Year Progress Report on Infant Imitation with Implications for Comparative Psychology. In B. G. Galef \& C. M. Heyes (Eds.), Social learning in animals: The roots of culture (pp. 347-370). New York: Academic Press.

Meltzoff, A. N. (1988). Infant imitation and memory: Nine-month-olds in immediate and deferred tests. Child Development, 59, 217-225.

Meltzoff, A. N., \& Gopnik, A. (1993). The role of imitation in understanding persons and developing a theory of mind. In S. Baron-Cohen, H. Tager-Flusberg, \& D. J. Cohen (Eds.), Understanding other minds: Perspectives from autism (pp. 335-366). Oxford: Oxford University Press.

Milton, K. (1981). Distribution patterns of tropical plant foods as a stimulus to primate mental development. American Anthropologist, 83, 534-548.

Milton, K. (1988). Foraging behaviour and the evolution of intellect in monkeys, apes and humans. In R. W. Byrne \& A. Whiten (Eds.), Machiavellian intelligence: Social expertise and the evolution of intellect in monkeys, apes and humans (pp. 285-305). Oxford: Clarendon Press.

Mitchell, R. W. (1993). Mental models of mirror-self-recognition: Two theories. New Ideas in Psychology, 11, 295-325.

Mithen, S. (1996). The prehistory of the mind. London \& New York: Thames \& Hudson.

Mountain, J. (1998). Molecular evolution and modern human origins. Evolutionary Anthropology, 7, 21-37.

Oakley, K. P. (1949). Man the tool maker. London: Trustees of the British Museum.

Packer, C. (1977). Reciprocal altruism in olive baboons. Nature, 265, 441-443. 
Parker, S. T. (1996). Apprenticeship in tool-mediated extractive foraging: The origins of imitation, teaching and self-awareness in great apes. In A. Russon, K. Bard, \& S. T. Parker (Eds.), Reaching into thought (pp. 348-370). Cambridge: Cambridge University Press.

Parker, S. T., \& Gibson, K. R. (1979). A developmental model for the evolution of language and intelligence in early hominids. Behavioral and Brain Sciences, 2, 367-408.

Parker, S. T., Mitchell, R. W., \& Boccia, M. L. (1994). Self-awareness in animals and humans: Developmental perspectives. Cambridge: Cambridge University Press.

Passingham, R. E. (1981). Primate specializations in brain and intelligence. Symposia of the Zoological Society of London, 46, 361-388.

Patterson, F. G. B., \& Cohn, R. H. (1994). Self-recognition and self-awareness in lowland gorillas. In S. T. Parker, R. W. Mitchell, \& M. L. Boccia (Eds.), Self-awareness in animals and humans: Developmental perspectives (pp. 273-290). Cambridge: Cambridge University Press.

Pawlowski, B., Lowen, C. B., \& Dunbar, R. I. M. (1998). Neocortex size, social skills and mating success in primates. Behaviour, 135, 357-368.

Perrett, D. I., Harries, M., H, Bevan, R., Thomas, S., Benson, P. J., Mistlin, A. J., Chitty, A. J., Hietanen, J. K., \& Ortega, J. E. (1989). Frameworks of analysis for the neural representations of animate objects and actions. Journal of Experimental Biology, 146, 87-113.

Povinelli, D. J., \& Cant, J. G. H. (1995). Arboreal clambering and the evolution of self-conception. Quarterly Journal of Biology, 70, 393-421.

Povinelli, D. J., Nelson, K. E., \& Boysen, S. T. (1992). Comprehension of role reversal in chimpanzees: Evidence of empathy? Animal Behaviour, 43, 633-640.

Povinelli, D. J., Parks, K. A., \& Novak, M. A. (1991). Do rhesus monkeys (Macaca mulatta) attribute knowledge and ignorance to others? Journal of Comparative Psychology, 105, 318-325.

Premack, D., \& Woodruff, G. (1978). Does the chimpanzee have a theory of mind? Behavioral and Brain Sciences, 4, 515-526.

Ridley, M. (1986). Evolution and classification: The reformation of cladism. London: Longman.

Ridley, M. (1993). Evolution. Oxford: Blackwell Scientific Publications.

Russon, A. E. (1996). Imitation in everyday use: matching and rehearsal in the spontaneous imitation of rehabilitant orangutans (Pongo pygmaeus). In A. E. Russon, K. A. Bard, \& S. T. Parker (Eds.), Reaching into thought: The minds of the great apes (pp. 152-176). Cambridge, UK: Cambridge University Press.

Russon, A. E., \& Galdikas, B. M. F. (1993). Imitation in free-ranging rehabilitant oragutans. Journal of Comparative Psychology, 107, 147-161.

Russon, A. E., \& Galdikas, B. M. F. (1995). Constraints on great ape imitation: model and action selectivity in rehabilitant orangutan (Pongo pymaeus) imitation. Journal of Comparative Psychology, 109, 5-17.

Sarich, V., \& Wilson, A. (1967). Immunological time scale for hominid evolution. Science, 158, 1200-1203.

Savage-Rumbaugh, E. S., Murphy, J., Sevcik, R. A., Brakke, K. E., Williams, S. L., \& Rumbaugh, D. M. (1993). Language comprehension in ape and child. Monographs of the Society for Research in Child Development, 58, 1-252.

Schaller, G. B. (1963). The mountain gorilla. Chicago: Chicago University Press.

Seyfarth, R., \& Cheney, D. (1984). Grooming alliances and reciprocal altruism in vervet monkeys. Nature, 308, $541-542$.

Shea, B. T. (1983). Phyletic size change and brain/body allometry: a consideration based on the African pongids and other primates. International Journal of Primatology, 4, 33-61.

Smuts, B. B. (1983). Special relationships between adult male and female olive baboons: Selective advantages. In R. A. Hinde (Ed.), Primate social relationships (pp. 262-266). Oxford: Blackwell.

Smuts, B. B. (1985). Sex and friendship in baboons. New York: Aldine Hawthorn.

Spence, K. W. (1937). Experimental studies of learning and higher mental processes in infra-human primates. Psychological Bulletin, 34, 806-850.

Stephan, H., Frahm, H., \& Baron, G. (1981). New and revised data on the brain structures in insectivores and primates. Folia primatologica, 35, 1-29.

Stringer, C., \& Gamble, C. (1993). In search of the Neanderthals. London \& New York: Thames \& Hudson.

Strum, S. C. (1983). Use of females by male olive baboons (Papio anubis). American Journal of Primatology, 5, 93-109.

Tanner, J. E., \& Byrne, R. W. (1996). Representation of action through iconic gesture in a captive lowland gorilla. Current Anthropology, 37, 162-173. 
Tattersall, I. (1995). The fossil trail. How we know what we think we know about human evolution. Oxford: Oxford University Press.

Teleki, G. (1973). The predatory behaviour of wild chimpanzees. East Brunswick, NJ: Bucknell University Press.

Tomasello, M., \& Call, J. (1997). Primate cognition. New York: Oxford University Press.

Tomasello, M., Call, J., Nagell, C., Olguin, R., \& Carpenter, M. (1994). The learning and use of gestural signals by young chimpanzees: A trans-generational study. Primates, 35, 137-154.

Tomasello, M., Gust, D., \& Frost, T. A. (1989). A longitudinal investigation of gestural communication in young chimpanzees. Primates, 30, 35-50.

Tomasello, M., Savage-Rumbaugh, E. S., \& Kruger, A. C. (1993). Imitative learning of actions on objects by children, chimpanzees, and enculturated chimpanzees. Child Development, 64, 1688-1705.

Tooby, J., \& Cosmides, L. (1992). The psychological foundations of culture. In J. H. Barkow, L. Cosmides, \& J. Tooby (Eds.), The adapted mind (pp. 19-136). New York: Oxford University Press.

Toth, N., Schick, K. D., Savage-Rumbaugh, E. S., Sevcik, R. A., \& Rumbaugh, D. M. (1993). Pan the tool-maker: Investigations into the stone-tool-making and tool-using capabilities of a bonobo (Pan paniscus). Journal of Archaeological Science, 20, 81-91.

van Schaik, C. P. (1983). Why are diurnal primates living in groups? Behaviour, 87, 120-147.

van Schaik, C. P., Fox, E. A., \& Sitompul, A. F. (1996). Manufacture and use of tools in wild Sumatran orangutans. Implications for human evolution. Naturwissenschaften, 83, 186-188.

Visalberghi, E., \& Fragaszy, D. M. (1990). Do monkeys ape? In S. T. Parker \& K. R. Gibson (Eds.), "Language” and intelligence in monkeys and apes (pp. 247-273). Cambridge: Cambridge University Press.

Visalberghi, E., \& Limongelli, L. (1994). Lack of comprehension of cause-effect relationships in tool-using capuchin monkeys (Cebus apella). Journal of Comparative Psychology, 103, 15-20.

Visalberghi, E., \& Trinca, L. (1987). Tool use in capuchin monkeys: Distinguishing between performing and understanding. Primates, 30, 511-521.

Waddell, P. J., \& Penny, D. (1996). Evolutionary trees of apes and humans from DNA sequences. In A. J. Lock \& C. R. Peters (Eds.), Handbook of symbolic evolution (pp. 53-73). Oxford: Clarendon Press.

Westergaard, C. G., \& Fragaszy, D. (1987). The manufacture and use of tools by capuchin monkeys (Cebus apella). Journal of Comparative Psychology, 101, 159-168.

White, T. D., Suwa, G., \& Asfaw, B. (1994). Australopithecus ramidus, a new species of early hominid from Aramis, Ethiopia. Nature, 371, 306-312.

Whiten, A. (1998). Imitation of the sequential structure of actions by chimpanzees (Pan troglodytes). Journal of Comparative Psychology, 112, 270-281.

Whiten, A. (1999). Parental encourangement in Gorilla in comparative perspective: implications for social cognition and the evolution of teaching. In S. T. Parker, H. L. Miles, \& R. W. Mitchell (Eds.), The mentality of gorillas and orangutans (pp. 342-365). Cambridge: Cambridge University Press.

Whiten, A., \& Byrne, R. W. (1988). Taking Machiavellian intelligence apart. In R. W. Byrne \& A. Whiten (Eds.), Machiavellian intelligence: Social expertise and the evolution of intellect in monkeys, apes and humans (pp. 50-65). Oxford: Oxford University Press.

Whiten, A., \& Byrne, R. W. (1991). The emergence of metarepresentation in human ontogeny and primate phylogeny. In A. Whiten (Ed.), Natural theories of mind: Evolution, development and simulation of everyday mindreading (pp. 267-281). Oxford: Basil Blackwell.

Whiten, A., \& Ham, R. (1992). On the nature and evolution of imitation in the animal kingdom: reappraisal of a century of research. In P. J. B. Slater, J. S. Rosenblatt, C. Beer, \& M. Milinski (Eds.), Advances in the study of behavior (pp. 239-283). San Diego: Academic Press.

Wilson, M., \& Daly, M. (1992). The man who mistook his wife for a chattel. In J. H. Barkow, L. Cosmides, \& J. Tooby (Eds.), The adapted mind (pp. 289-322). New York: Oxford University Press.

Wright, R. V. S. (1972). Imitative learning of a flaked-tool technology: The case of an orangutan. Mankind, 8, 296-306.

Wynn, T. (1988). Tools and the evolution of human intelligence. In R. W. Byrne \& A. Whiten (Eds.), Machiavellian intelligence: Social expertise and the evolution of intellect in monkeys, apes and humans (pp. 271-284). Oxford: Clarendon Press. 